\title{
Chemical Composition and Particle Size Analysis of Kaolin
}

\section{Shehu Yahaya ${ }^{1,2}$, Suzi Salwah Jikan ${ }^{1}$, Nur Azam Badarulzaman ${ }^{1}$, Ajiya Dahiru Adamu ${ }^{1,3}$}

${ }^{1}$ Universiti Tun Hussein Onn Malaysia

101 Beg Berkunci, Parit Raja, Batu Pahat, Johor, 86400, Malaysia

${ }^{2}$ Niger State Polytechnic

Along Zungeru / Wushishi / Bida Road, P. M. B. 01, Zungeru, Nigeria

${ }^{3}$ Abubakar Tafawa Balewa University

Tawafa Belewa Way, P. M. B. 0248, Bauchi, 740272, Nigeria

DOI: $10.22178 /$ pos.27-1

LCC Subject Category: QD1-999

Received 05.09.2017

Accepted 10.10.2017

Published online 17.10.2017

Corresponding Author: Shehu Yahaya yashe46@yahoo.com

(C) 2017 The Authors. This article is licensed under a Creative Commons Attribution 4.0 License @) (1)

\begin{abstract}
The mineral and elemental composition, crystal structure and particle size distribution of kaolin clays have been determined to ascertain its industrial significance. The mineral composition is evaluated by X- Ray Fluorescence (XRF), crystalline structure by X-Ray Diffraction (XRD) and particle size distribution using low angle laser light scattering (LALLS) technique. The results shows the presence of eight elements expressed in percentages in form of their oxides as: $\mathrm{SiO}_{2}$, $\mathrm{Al}_{2} \mathrm{O}_{3}, \mathrm{Fe}_{2} \mathrm{O}_{3}, \mathrm{MgO}, \mathrm{CaO}, \mathrm{K}_{2} \mathrm{O}, \mathrm{TiO}_{2}$ and $\mathrm{P}_{2} \mathrm{O}_{5}$. Five crystalline structures are revealed by XRD result. The particle size distribution shows that kaolin particles are mainly in the range of $25-35 \mu \mathrm{m}$, while few particles have size distribution varied between $0.4-0.75 \mu \mathrm{m}$. The report is found to be in agreement with other researchers.
\end{abstract}

Keywords: Kaolin; particle Size; composition; X- Ray Fluorescence; X-Ray Diffraction.

\section{INTRODUCTION}

The name kaolin was derived from a hill in China (Kao-ling) where it was mined for centuries [1]. Kaolin is a significant raw material with widespread application in industrial arena including water treatment, as porcelain, cement and ceramics production [2] and equally use as fillers for polymer, paint and rubber [3, 4]. Kaolin, or china clay, nevertheless relatively rare in nature, is of specific importance to the potter. It is fundamental in the manufacture of clean white porcelain. It consists of the main mineral referred to as kaolinite. The kaolin is composed of abundantly $1: 1$ clay mineral $\mathrm{Al}_{2} \mathrm{Si}_{2} \mathrm{O}_{5}(\mathrm{OH})_{4}$ structure per alumina-silicate producing bulky congested particles of $\mathrm{SiO}_{4}$ tetrahedral sheets and $\mathrm{AlO}_{2}(\mathrm{OH})_{4}$ octahedral sheets [5]. The AlOHOSi hydrogen bonds is attached to each two unbroken layers since the kaolinite layer is neutral. There is a formation of an asymmetric environment of octahedral sheets which have hydroxyl groups on the interlayer surface, however the tetrahedral sheets possess oxide surfaces. These layers are less tightly bonded through Vander Waal forces together through the 'c-axis' direction. The internal surface $\mathrm{OH}$ groups are located virtually perpendicular to the tetrahedral sheet of the next layer preceding to creation of intensive hydrogen bonds. Hence, kaolinite has been categorised as a non-expandable mineral [6].

Some other minerals such as quartz, feldspar, anatase, and muscovite are found typically in kaolin [7]. Furthermore, crude kaolin is regularly marked yellow by iron hydroxide pigments. It is frequently essential to decolourise the clay chemically to eliminate the iron pigment and to rinse it with water to detach the other minerals, or delaminate in order to formulate kaolin for different industrial uses $[8,9,10]$.

Kaolin can be used as an economical additive which can produce even dispersions to improve the properties of the product. The major characteristics of kaolin which are crucial for industrial uses includes particle size distribution, structural order, particle shape, disorder and crystallinity, specific surface area and whiteness [11]. Huge 
amount of numerous properties of kaolin are regulated by the surface properties of the kaolin. Predominantly in industries, substantial loadings and viscosity are essential, these also comprise of the occurrence of absorbed surface species which modify its properties [12].

Additionally, many industrial methods use particle size as a considerable factor $[13,14]$. The chemical, mechanical, and optical properties, the mixing behaviour and the bio-distribution of numerous resources and end-products are influenced by the size and shape of the particles. The results achieved by the particle size analysis involves volume distribution, standard mean diameters and distribution reports using the assumption that particles are spherical. The kaolin samples can be quantified through laser diffraction technique by bimodal distribution.

This study reports on the result on investigation of chemical constituents and particle size distribution of kaolin clay using X-Ray Fluorescence and FRITSCH Laser Particle Sizer respectively. The result is aimed to study the chemical composition and particle size distribution of kaolin obtained from an indigenous dealer Kaolin (Malaysia) Sdn. Bhd.

\section{MATERIALS AND METHODS}

Kaolin for this study was obtained from Kaolin (Malaysia) Sdn. Bhd in powdered form. By the use of hard-pressed with hydraulic press, powdered kaolin and wax were cautiously mixed and hard-pressed into pellets of $17 \mathrm{~mm}$ diameter in the ratio 8:2, powder to wax. 8 tonnes of $\mathrm{MPa}$ were operated for one minute to form the pellets. Consequently, samples were loaded in the XRF machine model (XRF Bruker S4 Pioneer) for elemental analysis. The machine was operated at maximum voltage and current $60 \mathrm{KV}$ and $1 \mathrm{~mA}$ respectively to generate the $\mathrm{X}$-rays which will energise the sample for a particular time (specifically, 10 mins) with X-ray tube of rhodium anode and scintillation detector of current $40 \mathrm{~mA}$ and voltage $40 \mathrm{mV}$. X-ray powder diffraction analysis was carried out using CuKa1 $(\lambda=1.54060 \AA)$ radiation at $0.3 / \mathrm{min}$ scanning rate of $2 \theta$ range of $5-40^{\circ}$ in a signal mode, with 0.03 phase size at room temperature on XPERT-3powder diffractometer fortified with a curved position-sensitive detector. The configurations were verified at $40 \mathrm{~mA}, 40 \mathrm{kV}$, and tests were positioned on flat bottom holder.
Particle size testing was conducted using FRITSCH Laser Particle Sizer (ANALYSETTE 22). Unique of the predefined Standard Operating Procedures (SOPs) ISO 13320 was chosen to start a measurement with the ANALYSETTE 22. The package encourages the adding of sample material [15]. The moment the quantity of sample is adequate, the measurement starts automatically. Subsequently, automatic dispersion, measurement, analysis and report generation occurs simultaneously. The system identifies, duplicates and evaluates with accuracy.

\section{RESULTS AND DISCUSSION}

\section{XRF Analysis}

The method of Elemental analyses of clays has been continuously showing the class of aluminosilicates to which the analyzed material correspond [16]. The elements determined in clays have been presented as relative percentage of the elements expressed as oxides in the whole sample as shown Table 1.

Table 1 - Mineralogical composition (XRF) of kaolin sample

\begin{tabular}{|c|c|c|c|c|c|c|c|}
\hline \multicolumn{7}{|c|}{ Sample Chemical composition (Weight \%) } \\
\hline $\mathrm{SiO}_{2}$ & $\mathrm{Al}_{2} \mathrm{O}_{3}$ & $\mathrm{Fe}_{2} \mathrm{O}_{3}$ & $\mathrm{MgO}$ & $\mathrm{CaO}$ & $\mathrm{K}_{2} \mathrm{O}$ & $\mathrm{TiO}_{2}$ & $\mathrm{P}_{2} \mathrm{O}_{5}$ \\
\hline 57.633 & 37.766 & 0.86 & 0.596 & 0.346 & 1.801 & 0.605 & 0.311 \\
\hline
\end{tabular}

According to reports by [1] the Malaysian kaolin has high amount of silica $69.30 \%$ and lower alumina $24.30 \%$. Other researchers [17] achieved silica content of $56.290 \%$ and alumina $36.490 \%$; which is related to this report.

\section{XRD Analysis}

Figure 1 represents the XRD diffractograms of the kaolin.

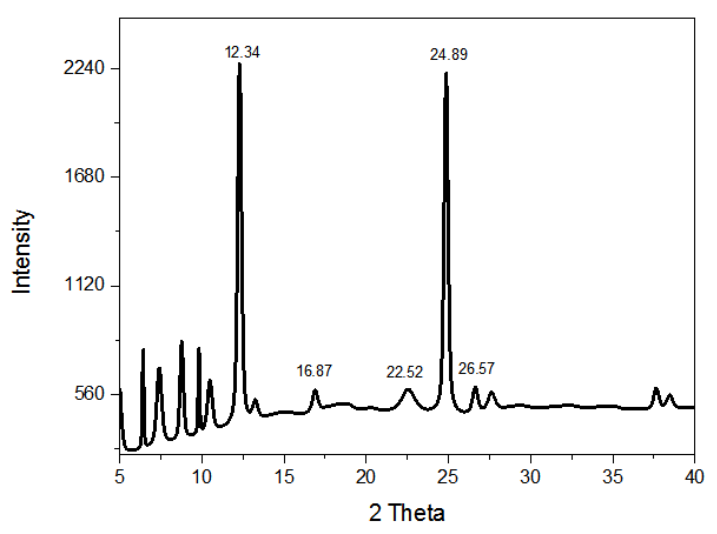

Figure 1 - XRD diffractograms of the kaolin 
Five prominent peaks are detected at about $12.34^{\circ}, 16.87^{\circ}, 22.52^{\circ}, 24.89^{\circ}$ and $26.88^{\circ}$. The peak at $2 \theta=12.34^{\circ}$ is the distinctive XRD form of kaolin. The XRD diffractograms displays the exis- tence of five crystalline phases as summarised in Table 2 below. This report supports the XRF result obtained above.

Table 2 - Crystalline phases from XRD result

\begin{tabular}{|l|l|l|l|}
\hline \multicolumn{1}{|c|}{ Phase } & \multicolumn{1}{c|}{ Shape } & \multicolumn{1}{c|}{ Formulae } & \multicolumn{1}{c|}{ Reference code } \\
\hline Silicon Dioxide & Hexagonal & $\mathrm{SiO}_{2}$ & ICSD 98-017-1734 \\
\hline Zeolite SSZ-16 & Orthorhombic & $\mathrm{H}_{4.14} \mathrm{Al}_{7.2} \mathrm{Na}_{3.06} \mathrm{Si}_{40.8}$ & ICSD 98-062-6844 \\
\hline Quartz low & Hexagonal & $\mathrm{O}_{2} \mathrm{Si}$ & ICSD 98-002-0145 \\
\hline Carbon oxide Lt & Cubic & $\mathrm{CO}$ & ICSD 98-002-6962 \\
\hline 13-Carbonylcarbidotetrairon & Monoclinic & $\mathrm{C}_{14} \mathrm{Fe}_{4} \mathrm{O}_{13}$ & ICSD 98-002-1070 \\
\hline
\end{tabular}

\section{Particle size distribution}

Figure 2 represents the distribution of particles in relation to particle diameter vs percentage of total particle volume of kaolin samples, as evaluated by dimensions of low angle laser light scattering (LALLS) technique.

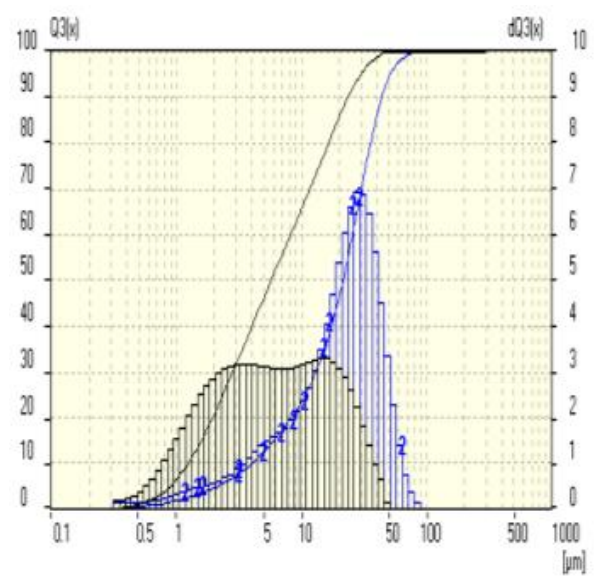

Figure 2 - Particle size distribution of kaolin

From figure 2, the particle-size dispersion of kaolin (blue line) indicates the existence of two particles assortment of sizes interchanging between 0.3 and $100 \mu \mathrm{m}$. The highest dispersion $(\sim 70 \%)$ is produced by particles of $25-35 \mu \mathrm{m}$, with $30 \mu \mathrm{m}$ modal size. This population complements through a lesser collection $(\sim 3 \%)$ which involves particles of $0.4-0.75 \mu \mathrm{m}$, having $0.5 \mu \mathrm{m}$ modal size. The particles has arithmetic mean diameter (De Brouckeremean diameter, $D_{4,3}$ ), span value (the distribution of width of size $\left(\mathrm{d}_{90}\right.$ $\left.\mathrm{d}_{10}\right) / \mathrm{d}_{50}$ ) and the median particle size $\mathrm{d}_{50}$ of $8.343,3.653$ and 5.227 respectively.

\section{CONCLUSION}

Kaolin is found to be a beneficial mineral resource not merely as a worthy basis of silica, but likewise as the origin of zeolite, quartz, and carbon oxide and carbonyl materials. This can potentially allow the manufacture of collection of valued products. Though, there is need for higher perspectives of kaolin for merchandise improvement. The study has offered altogether a valuable know-how on the compositional and particle size features of kaolin sample. Hence, additional information on the composition and particle size analysis of kaolin is appropriately imperative for the purpose of which variety of kaolin can be expended by manufacturing industries.

\section{ACKNOWLEDGEMENTS}

This study was sponsored by financial support of Universiti Tun Hussein Onn Malaysia, (UTHMORICC) (Vote U303).

\section{REFERENCES}

1. Jamo, H. U., \& Abdu, S. G. (2014). Structural analysis and surface morphology kaolin. Science World Journal, 9(3), 29-30.

2. Lima, P. A., Angélica, R., \& Neves, R. (2017). Dissolution kinetics of Amazonian metakaolin in hydrochloric acid. Clay Minerals, 52(1), 75-82. doi: 10.1180/claymin.2017.052.1.05 
3. Kotal, M., \& Bhowmick, A. K. (2015). Polymer nanocomposites from modified clays: Recent advances and challenges. Progress in Polymer Science, 51, 127-187. doi:

10.1016/j.progpolymsci.2015.10.001

4. Liu, P., Farzana, R., Rajarao, R., \& Sahajwalla, V. (2017). Lightweight expanded aggregates from the mixture of waste automotive plastics and clay. Construction and Building Materials, 145, 283291. doi: 10.1016/j.conbuildmat.2017.04.009

5. Jikan, S. S., Badarulzaman, N. A., Yahaya, S., \& Adamu, A. D. (2017). Delamination of Kaolinite by Intercalation of Urea Using Milling. Materials Science Forum, 888, 136-140. doi: 10.4028/www.scientific.net/msf.888.136

6. Abou-El-Sherbini, K. S., Elzahany, E. A. M., Wahba, M. A., Drweesh, S. A., \& Youssef, N. S. (2017). Evaluation of some intercalation methods of dimethylsulphoxide onto HCl-treated and untreated Egyptian kaolinite. Applied Clay Science, 137, 33-42. doi: 10.1016/j.clay.2016.12.005

7. Sengupta, P., Saikia, P., \& Borthakur, P. C. (2008). SEM-EDX characterization of an iron-rich kaolinite clay. Journal of Scientific \& Industrial Research, 67, 812-818.

8. Nazir, M. S., Mohamad Kassim, M. H., Mohapatra, L., Gilani, M. A., Raza, M. R., \& Majeed, K. (2016). Characteristic Properties of Nanoclays and Characterization of Nanoparticulates and Nanocomposites. Engineering Materials, 35-55. doi: 10.1007/978-981-10-1953-1_2

9. Tang, W., Song, L., Zhang, S., Li, H., Sun, J., \& Gu, X. (2016). Preparation of thiourea-intercalated kaolinite and its influence on thermostability and flammability of polypropylene composite. Journal of Materials Science, 52(1), 208-217. doi: 10.1007/s10853-016-0323-8

10. Sempeho, S. I., Kim, H. T., Mubofu, E., Pogrebnoi, A., Shao, G., \& Hilonga, A. (2015). Dynamics of Kaolinite-Urea Nanocomposites via Coupled DMSO-Hydroxyaluminum Oligomeric Intermediates. Indian Journal of Materials Science, 2015, 1-10. doi: 10.1155/2015/920835

11. Franco, F., Cecila, J. A., Pérez-Maqueda, L. A., Pérez-Rodríguez, J. L., \& Gomes, C. S. F. (2007). Particlesize reduction of dickite by ultrasound treatments: Effect on the structure, shape and particlesize distribution. Applied Clay Science, 35(1-2), 119-127. doi: 10.1016/j.clay.2006.07.004

12. Li, X., Liu, Q., Cheng, H., Zhang, S., \& Frost, R. L. (2015). Mechanism of kaolinite sheets curling via the intercalation and delamination process. Journal of Colloid and Interface Science, 444, 74-80. doi: 10.1016/j.jcis.2014.12.039

13. Jillavenkatesa, A., Dapkunas, S. J., \& Lum, L.-S. H. (2001, January). Particle Size Characterization. Retrieved from http://ws680.nist.gov/publication/get_pdf.cfm?pub_id=850451

14. Toraman, O. Y., \& Uçurum, M. (2017). Investigation of grinding-aid effect on the fineness, particle size distribution, surface area and color properties of calcite powder in dry vertical stirred mill. Chemistry Research Journal, 2(3), 56-65.

15. Malvern Instruments Limited (2012). A basic guide to particle characterization. Retrieved August 10, 2017, from

http://www.cif.iastate.edu/sites/default/files/uploads/Other_Inst/Particle\%20Size/Particle\%2 0Characterization\%20Guide.pdf

16. Gates, W. P., Slade, P. G., Manceau, A., \& Lanson, B. (2002). Site Occupancies by Iron in Nontronites. Clays and Clay Minerals, 50(2), 223-239. doi: 10.1346/000986002760832829

17. Aroke, U. O., \& El-Nafaty, U. A. (2014). XRF, XRD and FTIR properties and characterization of HDTMA-Br surface modified organo-kaolinite clay. International Journal of Emerging Technology and Advance Engineering, 4(4), 817-825. 